\title{
Effects of alloy elements on ductility and thermal conductivity of compacted graphite iron
}

\author{
Dong-mei Xu', Gui-quan Wang', *Xiang Chen ${ }^{1,2}$, Yan-xiang Lí, ${ }^{1,2}$, Yuan Liu', \\ 1. School of Materials Science and Engineering, Tsinghua University, Beijing 100084, China \\ 2. Key Laboratory for Advanced Materials Processing Technology (MOE), Tsinghua University, Beijing 100084, China
}

\begin{abstract}
The influence of $\mathrm{Si}, \mathrm{Sn}, \mathrm{Mo}$ and $\mathrm{Ni}$ on the ductility and thermal conductivity of compacted graphite iron (CGI) was investigated. Metallographic observation and Differential Scanning Calorimetry (DSC) experiments were carried out to analyze the roles of various additions in the eutectoid reaction. The experimental results showed that the ductility of $\mathrm{CGI}$ is proportional to the ferrite fraction, so moderate Si content could dramatically improve the ductility by increasing the ferrite fraction. DSC measurements showed that Mo has moderate inhibition on eutectoid transformation during both the heating and cooling processes, while the sample without $\mathrm{Sn}$ obviously broadens the three-phase region. Vermicularity and ferrite are known to improve thermal conductivity, and the former plays a more important role. Besides, among the alloy elements investigated, $\mathrm{Sn}$ has the greatest negative effect on conductivity, followed by $\mathrm{Ni}$ and Mo having the smallest effects.
\end{abstract}

Key words: compacted graphite iron; ductility; thermal conductivity

CLC numbers: TG143.2 Document code: A Article ID: 1672-6421(2018)03-189-07

$I^{1}$

response to strict environmental and customer

requirements, the peak firing pressure of engine has

been increasingly rising. As a result, the material applied to the engine must possess better performance than common grey cast iron or aluminum alloy to overcome the hostile working environment, which is bearing with massive heat and stress. In this study, compacted graphite iron with intermediate properties, i.e. better mechanical properties than grey cast iron and superior thermal conductivity than nodular cast iron, has been regarded as a new potential generation of engine material especially for the cylinder block and head.

Since ductility and thermal conductivity play an important role in thermal fatigue, the combination between them is worth of investigating to prolong the service life of the cylinder head ${ }^{[1]}$. Many studies ${ }^{[2-7]}$ have focused on the effects of alloy elements on eutectoid transformation of cast iron which associates with ductility, whereas others ${ }^{[8-13]}$ have studied the influence of chemical composition on the thermal property of cast iron. However, research

\section{*Xiang Chen}

Male, born in 1970, Associate Professor. His research and teaching interests are in the areas of cast alloying materials and porous metal materials.

E-mail: xchen@tsinghua.edu.cn

Received: 2018-04-25; Accepted: 2018-05-09

on both ductility and thermal conductivity can rarely be found. During the eutectoid transformation, Si has a positive effect on ferrite while other alloy elements usually act as pearlite promoter in $\mathrm{CGI}^{[2]}$. Mn promotes pearlite rather strongly compared with $\mathrm{Mo}^{[3]}$, but the extent is weaker compared with $\mathrm{Sn}^{[4]}$. For ductile iron, low-level addition of $\mathrm{Cu}$ below $0.5 \mathrm{wt} . \%$ does not decrease the ferrite fraction markedly, illustrated by differential thermal analysis (DTA) according to Lacaze ${ }^{[5]}$ and Sertucha ${ }^{[6]}$. Lacaze had further investigated the effects of $\mathrm{Cu}$ and $\mathrm{Sn}$ on pearlite. The results implied that $\mathrm{Cu}$ and $\mathrm{Sn}$ do not affect the growth kinetics of pearlite, while Sn (range from $0.05 \mathrm{wt} . \%$ to $0.1 \mathrm{wt} . \%$ ) strongly decreases the nucleation barrier for pearlite and increases the start transformation temperature, which is totally different from $\mathrm{Cu}^{[7]}$. The thermal property of cast iron mainly depends on the morphology of graphite, followed by the type of the metallic matrix ${ }^{[8-11]}$. Moreover, the chemical composition also plays an important role in thermal conductivity. Holmgren et al. believed that Si has a good graphitizing ability and strong solute solubility, but the negative effect of $\mathrm{Si}$ is also great, i.e., the greater the amount of $\mathrm{Si}$, the lower the thermal conductivity ${ }^{[12]}$. Alloy elements, for example, $\mathrm{Cr}, \mathrm{V}$, and Sn have been reported to cause moderate reductions in the thermal conductivity of cast iron ${ }^{[2,12,13]}$. However, it 
is paradox when talking about the effects of $\mathrm{Mo}$ and $\mathrm{Ni}$, which needs further clarification on the basis of the actual specific condition. Besides, the ductility of CGI reported by many researchers fluctuates at $2 \%$, and the thermal conductivity is less than $40 \mathrm{~W} \cdot \mathrm{m}^{-1} \cdot \mathrm{K}^{-1}$ in CGI with tensile strength more than 350 $\mathrm{MPa}$, which has poor cyclic-temperature loading fatigue and goes against the application of CGI in the cylinder block and head. Therefore, before the material with optimum properties can be achieved, it is vital to coordinate between good ductility and high thermal conductivity on the premise of a strength more than $350 \mathrm{MPa}$ through adjusting the composition.

The aim of the present work is to investigate the influence of $\mathrm{Si}, \mathrm{Sn}, \mathrm{Mo}$, and Ni on the ductility and thermal conductivity of CGI. Since ductility is mainly associated with the percentage of ferrite in the matrix, the influence of elements on ferrite rather than ductility was discussed. DSC was used to analyze the kinetics of the eutectoid transformation, which is an intuitive method, instead of traditional quenching experiment with a series of complicated processes. Then the order among these elements was concluded further and comprehensive properties, i.e. ductility more than $4 \%$ and thermal conductivity more than
$40 \mathrm{~W} \cdot \mathrm{m}^{-1} \cdot \mathrm{K}^{-1}$ as well as strength more than $350 \mathrm{MPa}$ can be achieved by composition optimization.

\section{Experiment}

\subsection{Material}

The experimental CGIs were melted by using a $500 \mathrm{~kg}$ capacity medium-frequency induction heating furnace. The charge material consisted of $340 \mathrm{~kg}$ pig iron, $160 \mathrm{~kg}$ steel scraps, carburant, ferrosilicon, ferromanganese, ferromolybdenum, sheet nickel, sheet copper and sheet tin. The CGI was melted at $1,550{ }^{\circ} \mathrm{C}$. After holding at the temperature for $5 \mathrm{~min}$, the melts were poured into furan sand molds at $1,360-1,380{ }^{\circ} \mathrm{C}$ to produce cast ingots sized according to the Chinese Standard GB/T 26655-2011. A high-frequency infrared C-S analyzer, HCS 140 from DEKAI Instruments, and a direct-reading spectrometer, ARL metal analyzer (iron+steel), were used to determine the chemical composition, which can be found in Table 1. In Table 1, the first four CGIs were applied to investigate the effects of $\mathrm{Si}$, while the last four irons were focused on the influence of $\mathrm{Sn}, \mathrm{Mo}$, and $\mathrm{Ni}$, respectively.

Table 1: Chemical composition of CGI (wt.\%)

$\begin{array}{cllllllllll}\text { Casting No. } & \mathbf{C} & \mathrm{Si} & \mathrm{Mn} & \mathbf{P} & \mathrm{S} & \mathrm{Cu} & \mathrm{Sn} & \mathrm{Mo} & \mathrm{Ni} \\ 1 & 3.59 & 1.79 & 0.37 & 0.03 & 0.032 & 0.42 & 0.034 & - & - \\ 2 & 3.59 & 2.11 & 0.38 & 0.039 & 0.017 & 0.42 & 0.034 & - & - \\ 3 & 3.57 & 2.33 & 0.41 & 0.031 & 0.012 & 0.42 & 0.034 & - & - \\ 4 & 3.50 & 2.76 & 0.40 & 0.033 & 0.015 & 0.41 & 0.032 & - & - \\ 5 & 3.55 & 2.32 & 0.40 & 0.029 & 0.013 & 0.42 & 0.003 & 0.19 & - \\ 6 & 3.57 & 2.43 & 0.39 & 0.031 & 0.012 & 0.41 & 0.036 & 0.21 & - \\ 7 & 3.60 & 2.40 & 0.38 & 0.033 & 0.012 & 0.41 & 0.036 & 0.22 & 0.21 \\ 8 & 3.62 & 2.39 & 0.39 & 0.032 & 0.014 & 0.41 & 0.037 & 0.28 & 0.19\end{array}$

\subsection{Metallography and mechanical test}

The microstructural evaluation of the CGI samples was examined on a ZEISS Axio Scope A1 optical microscope. Analysis on the unetched samples was performed to evaluate the vermicularity by roundness, according to Chinese Standard GB/T 26656-2011 and the graphite amount of the CGI samples. The samples were etched with $4 \%$ nital for 4 to $5 \mathrm{~s}$ and then the fractions of pearlite and ferrite were calculated using
Image-Pro Plus Software. The tensile test was performed on a WEW-3000 universal testing machine and the diameter of the specimens was $\Phi 14 \mathrm{~mm}$, processed according to the Chinese Standard GB/T 26655-2011. The data were measured at ambient temperature and the results were the mean value of two measurements. The microstructure data and tensile results are listed in Table 2.

Table 2: Mechanical properties of CGI

\begin{tabular}{|c|c|c|c|c|c|c|c|c|}
\hline \multirow{2}{*}{ Mechanical properties } & \multicolumn{8}{|c|}{ Casting No. } \\
\hline & 1 & 2 & 3 & 4 & 5 & 6 & 7 & 8 \\
\hline Tensile Strength (MPa) & 474 & 450 & 447 & 385 & 398 & 440 & 500 & 508 \\
\hline Ductility (\%) & 1.7 & 3.0 & 3.6 & 3.6 & 5.8 & 3.1 & 4.1 & 3.9 \\
\hline Thermal conductivity $\left(\mathrm{W} \cdot \mathrm{m}^{-1} \cdot \mathrm{K}^{-1}\right)$ & - & 35.9 & 46.2 & 36.4 & 35.7 & 32.2 & 29.1 & 28.9 \\
\hline Vermicularity (\%) & 74 & 82 & 90 & 87 & 77 & 77 & 71 & 83 \\
\hline Ferrite fraction (\%) & 14 & 20 & 31 & 51 & 66 & 37 & 32 & 30 \\
\hline
\end{tabular}




\subsection{Thermal conductivity test}

A Netzsch LFA 457 laser thermal conducting instrument was used to obtain the thermal conductivity which is calculated according to the following equation ${ }^{[8,14]}$.

$$
\lambda=\alpha \rho C_{\mathrm{p}}
$$

where $\alpha$ is the thermal diffusivity, $\rho$ is the bulk density and $C_{\mathrm{p}}$ is the specific heat. The density was measured by the Archimedes principle. The specific heat was obtained using a Netzsch DSC 404 C Pegasus differential scanning calorimeter. And the thermal diffusivity value was calculated with Cape-Lehman model and an average value was derived from three shots at ambient temperature.

\subsection{DSC experiments}

For further investigating the roles of alloying elements, the DSC experiments were carried out utilizing a NETZSCH STA 449 F3 Jupiter Simultaneous Thermal Analysis System. The samples were heated to $900{ }^{\circ} \mathrm{C}$ and held for $10 \mathrm{~min}$ so as to achieve the full transformation of austenite from pearlite and ferrite. It can be expected that the microstructure consists of austenite and graphite at this temperature. Then the samples were cooled down to $600{ }^{\circ} \mathrm{C}$ at the rate of $5{ }^{\circ} \mathrm{C} \cdot \mathrm{min}^{-1}$. It is believed to be a slow solidification process such as in a furan resin furan sand mold ${ }^{[14]}$
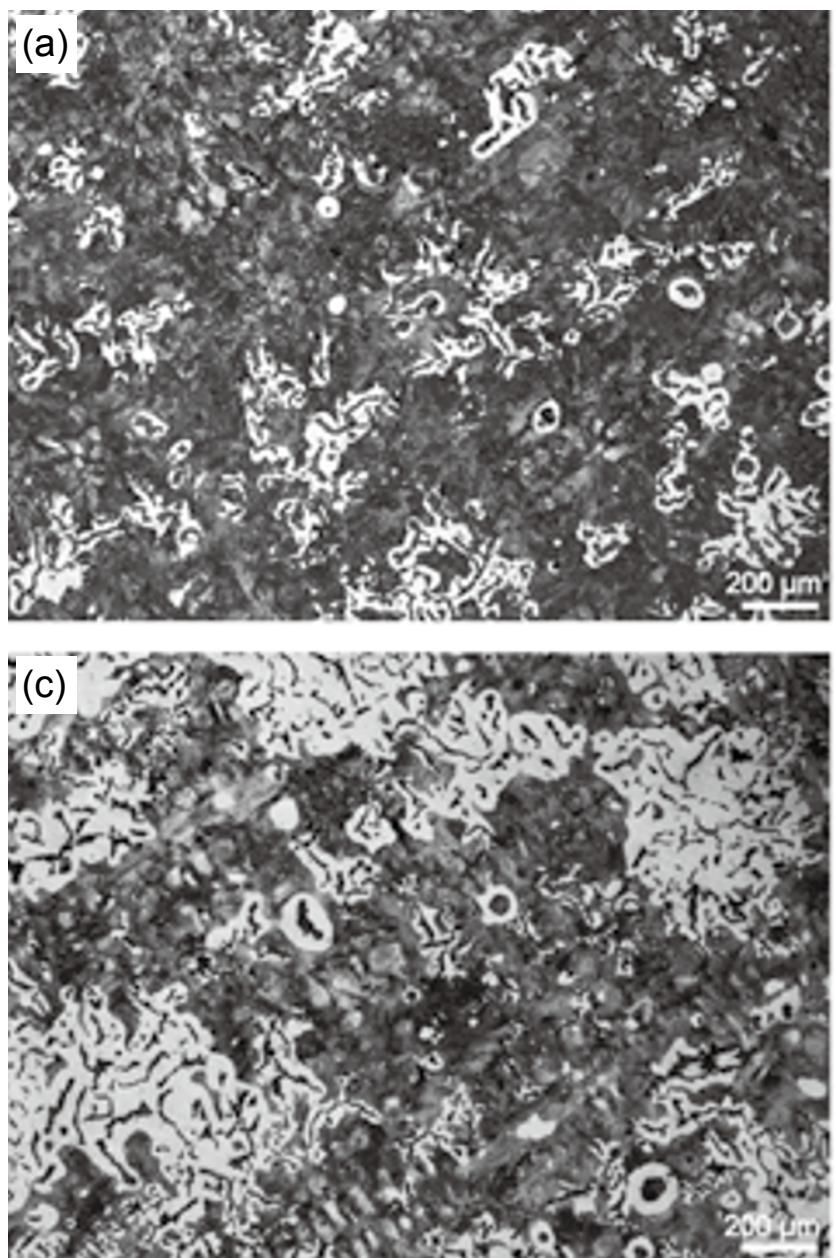

\section{Results and discussion}

\subsection{Microstructure and mechanical properties}

The results concerning ferrite fraction, vermicularity and mechanical properties are listed in Table 2. Comparing casting No. 3 and casting No.4 with similar vermicularity, it is clear that the effects of $\mathrm{Si}$ on the ferrite fraction and the mechanical properties are significant. Figure 1 shows the optical micrographs of the samples with different Si content, which obviously show that the amount of the ferrite increases with the increase of the Si content. It can be attributed to the higher start temperature of ferrite transformation, leading to the higher diffusion rates of the carbon atom, as well as the broader temperature range for ferrite growth. However, high Si content is detrimental to the mechanical properties of CGI when comparing the tensile strength of casting No.3 and one of the casting No.4. It is proposed that the solution hardening impact of Si results in the embrittlement of CGI, and consequently damage to the mechanical property ${ }^{[3]}$. Note that a moderate increase in the ductility accompanied by the increase of ferrite, as shown in Fig. 2, and the deviation mainly derives from different vermicularity. In order to achieve ductility more than $4 \%$, the ferrite fraction should be more than $40 \%$ according to the trend in the figure.
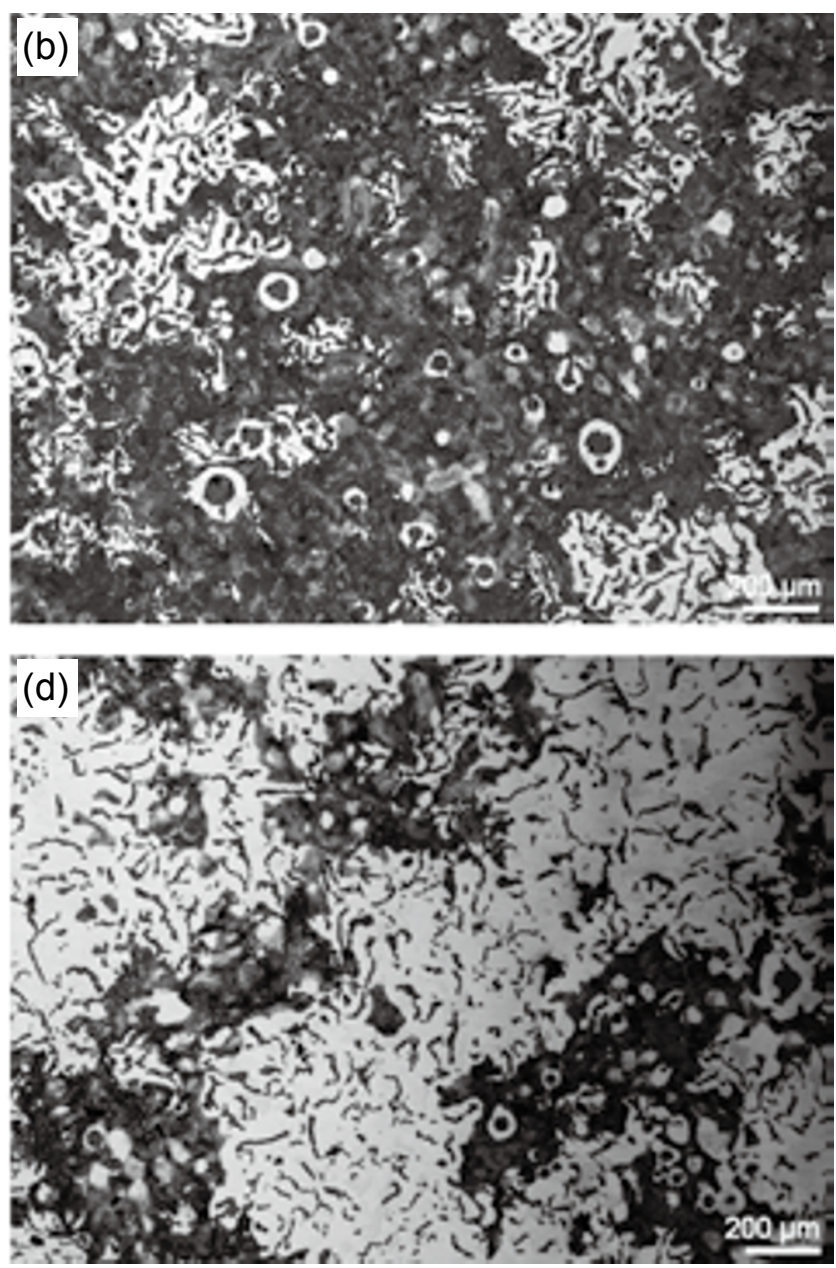

Fig. 1: Optical micrographs of samples etched with $4 \%$ nital (white part represents ferrite and dark part is the mixture of graphite and pearlite): (a) to (d) correspond to casting No. 1 to 4, respectively 


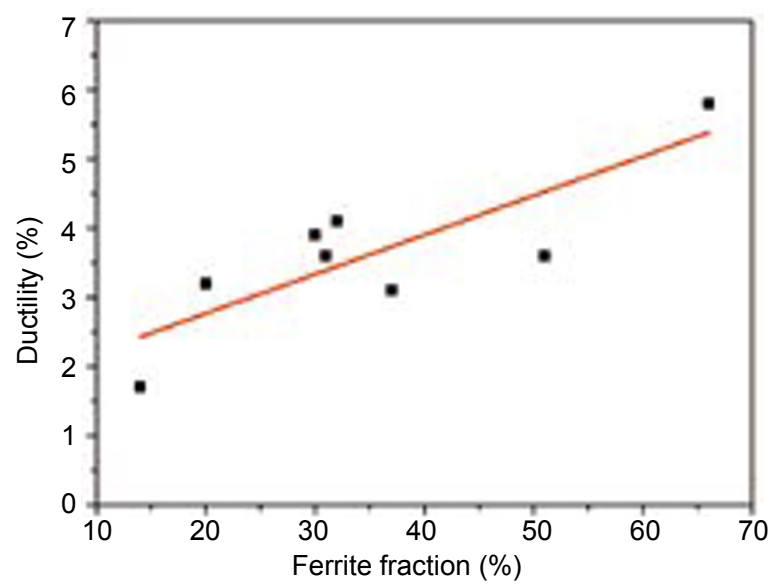

Fig. 2: Relationship between ductility and ferrite

When comparing casting No. 5 with casting No. 6 , the ferrite fraction is nearly double in correlation to the decrease of $\mathrm{Sn}$ from $0.036 \mathrm{wt} . \%$ to $0.003 \mathrm{wt} . \%$, together with the similar trend in ductility, i.e. rise from $3.1 \%$ to $5.8 \%$. The reason is mainly associated with the segregation of $\mathrm{Sn}$ at the interface between graphite and austenite, which restricts the graphite acting as a carbon sink, depresses the diffusion of carbon through the region around the graphite, and prevents the formation of ferrite on the basis of austenite $(\gamma \rightarrow \alpha+G)$ or cementite in pearlite $\left(\mathrm{Fe}_{3} \mathrm{C} \rightarrow \alpha+\mathrm{G}\right){ }^{[15]}$. The comparison among casting No. 6, 7 and 8 shows that Mo and Ni decrease the amount of ferrite slightly, but not like $\mathrm{Sn}$ that decreases the ferrite amount obviously. Due to the similar extent of effects on ferrite between Mo and $\mathrm{Ni}$, only Mo was taken for further analysis using DSC curves

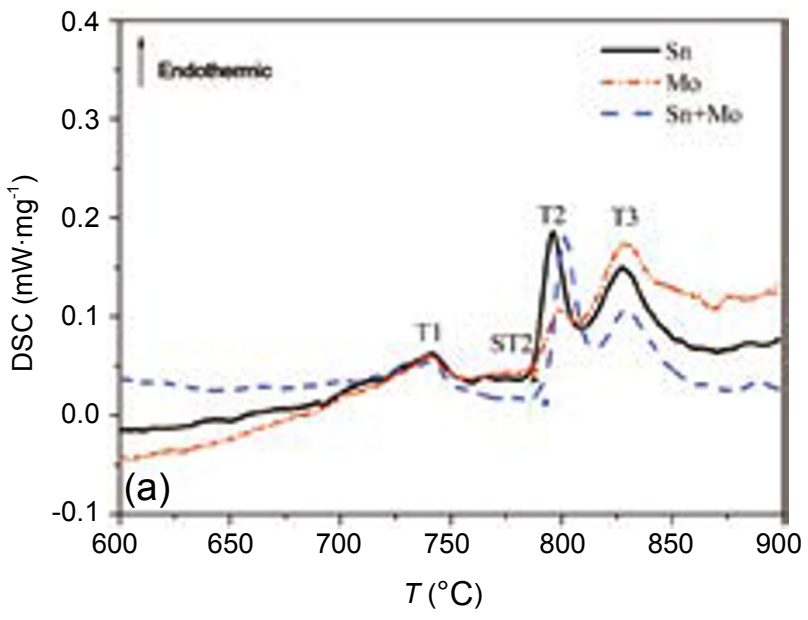

(a) First heating process as well as Sn. Therefore, samples used for DSC experiments were cut from casting No. 3, 5 and 6 and then they were used to reveal the effects of $\mathrm{Sn}, \mathrm{Mo}$, and $\mathrm{Sn}+\mathrm{Mo}$, respectively.

\subsection{DSC analysis}

Figure 3(a) shows the DSC curves of the CGI samples with different alloying elements during the heating period. For the eutectoid reaction of cast iron, it is widely accepted that two types of transformation are involved, namely stable and metastable transformation ${ }^{[15,16]}$. In Fig. 3(a), one can find that there appear three peaks for all the three DSC curves, denoted as $\mathrm{T} 1, \mathrm{~T} 2$ and $\mathrm{T} 3$. The characteristic temperature values are shown in Table 3 and the start temperature of peak T2 can be denoted as ST2. In order to recognize which two peaks correspond to the eutectoid reaction, Thermo-calc Software was used for reference. Figure 4 showed the stable phase diagram of $\mathrm{Fe}-\mathrm{C}-\mathrm{Si}$ at $2.4 \mathrm{wt} . \% \mathrm{Si}$, the temperature range of eutectoid three-phase region at 3.6wt.\% carbon is about $793-819{ }^{\circ} \mathrm{C}$. Therefore, it is evident that the last two peaks correspond to the three-phase region, i.e., T2 relates to pearlite and $\mathrm{T} 3$ associates with ferrite. Even though there is some discrepancy between the calculated temperature range and the measured one, i.e., around $780-850{ }^{\circ} \mathrm{C}$, the latter is worth believing because of the influence of overheating and higher heating rate. For the first peak of DSC profiles, it is believed that they correspond to the magnetic transformation at the Curie temperature which is around $740{ }^{\circ} \mathrm{C}$ in this study, lower than the Curie temperature of ferrite (about $770^{\circ} \mathrm{C}$ ) because of the addition of Si and alloying elements ${ }^{[17-19]}$.

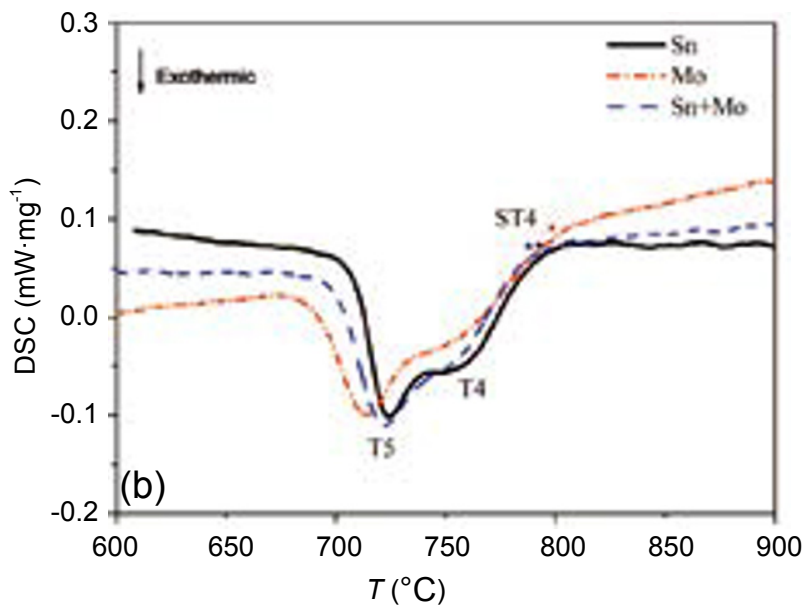

(b) Cooling period

Fig. 3: DSC profiles of CGI samples with different alloying elements

Table 3: Characteristic temperatures of DSC profiles $\left({ }^{\circ} \mathrm{C}\right)$

\begin{tabular}{|c|c|c|c|c|c|c|}
\hline Alloys & ST2 & T2 & T3 & ST4 & T5 & $\Delta \mathrm{T}$ \\
\hline $\mathrm{Si}$ & 786 & 795 & 827 & 746 & 712 & 34 \\
\hline Mo & 787 & 799 & 830 & 749 & 707 & 42 \\
\hline $\mathrm{Si}+\mathrm{Mo}$ & 792 & 802 & 828 & 744 & 711 & 33 \\
\hline
\end{tabular}




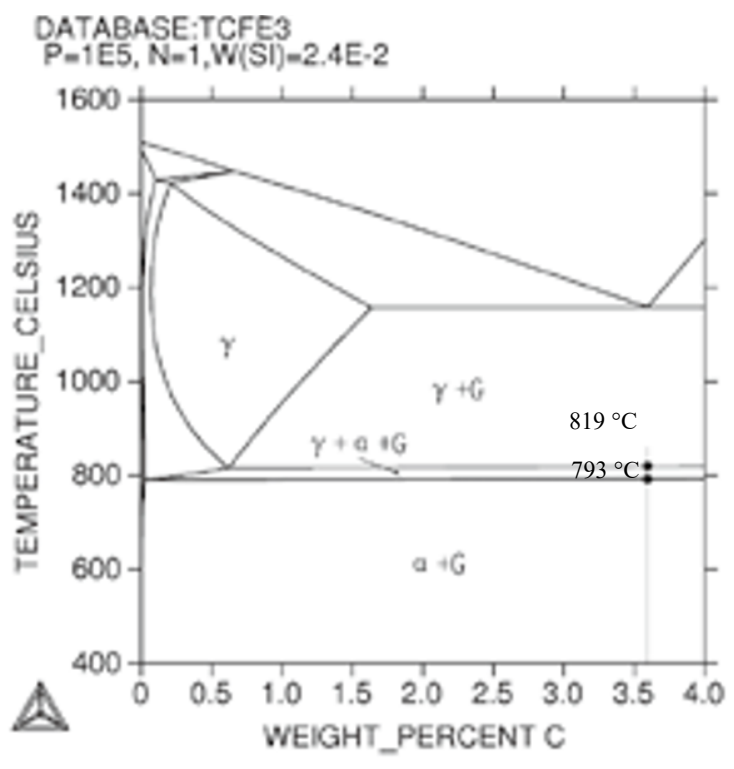

Fig. 4: Stable vertical section of Fe-C-Si at $2.4 \mathrm{wt} . \% \mathrm{Si}$
According to the values of ST2 in Table 3, similar start temperature values for pearlite austenitizing between the CGI with Sn and the CGI with Mo are observed. When Sn is added as well as Mo, the start temperature rises obviously. At the same time, the $\mathrm{T} 2$ values increase successively after adding $\mathrm{Sn}$ to $\mathrm{Mo}$, and to $\mathrm{Sn}+\mathrm{Mo}$. The conclusion can be drawn that both $\mathrm{Sn}$ and Mo can improve the temperature of phase transformation during heating, which contributes to enhancing the performance of CGI at the higher temperature. Comparing the shapes of the curves, the peak T2 after adding $\mathrm{Sn}$ is similar to that after adding $\mathrm{Sn}$ + Mo and is much higher and steeper than that after adding Mo. Since the peak area is associated with the phase fraction, ferrite fraction after adding Mo, i.e., the samples without $\mathrm{Sn}$, is the greatest, which keeps a good agreement with the data in Table 2 and micrographs in Fig. 5. This shows that Mo just has inconspicuous effects, while Sn strongly affects the shape of the DSC profile, further implying that Sn inhibits the ferrite transformation and improves the pearlite fraction much more intensely than Mo.
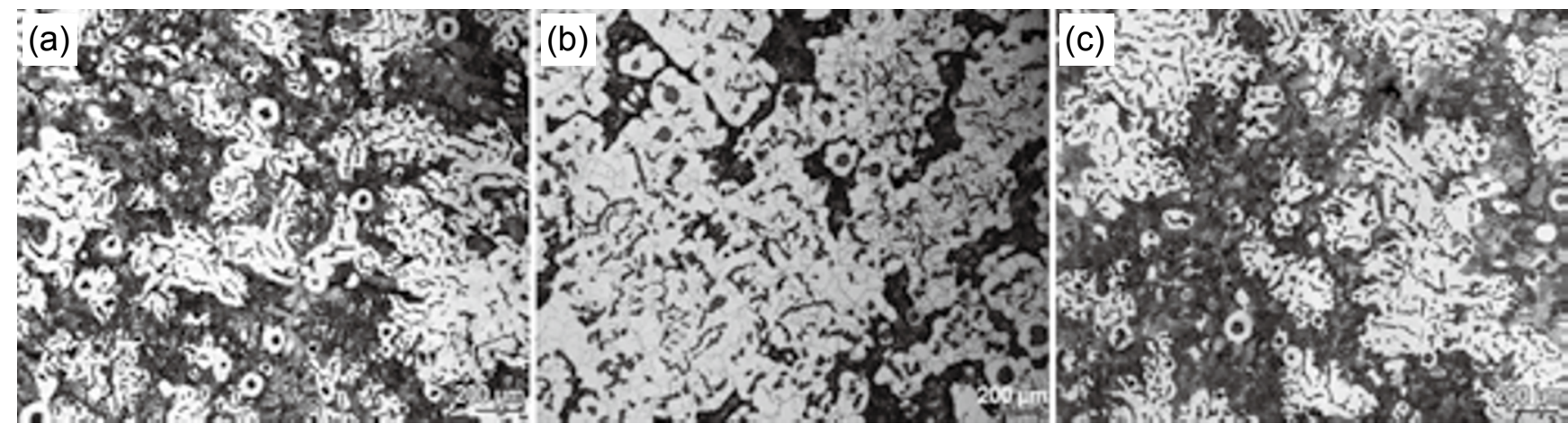

Fig. 5: Optical micrographs of samples etched with $4 \%$ nital (where the white part in the picture represents ferrite and the dark part is the mixture of graphite and pearlite): (a) to (c) correspond to casting No. 3 , No. 5 and No. 6 , respectively

Figure 3(b) illustrates the DSC profiles with two overlapped peaks during cooling, which is different from the profile during heating. Since the Curie temperature is about $740{ }^{\circ} \mathrm{C}$, the first peak downward denoted $\mathrm{T} 4$ corresponds to the ferrite reaction and the magnetic transformation. The second peak denoted T5 relates to the transformation of austenite to pearlite. ST4 represents the start temperature of ferrite transformation, which is significant because T4 is difficult to pinpoint. Different from the stable phase diagram and the DSC profiles during heating, the temperature range of the three-phase region in this period is about $700-750{ }^{\circ} \mathrm{C}$, because undercooling is required for nucleation. Otherwise, the results concerning the shapes among these three curves are quite similar to what was obtained and mentioned above, i.e., curves after adding Sn and $\mathrm{Sn}+\mathrm{Mo}$ are different from that after adding Mo. For the temperature range $\Delta T$ from ST4 to $\mathrm{T} 5$, the value in the sample without $\mathrm{Sn}$ is quite larger than that in the sample with $\mathrm{Sn}$, which can provide a higher temperature for the carbon diffusion and more time for the growth of ferrite. Therefore, no matter during heating or cooling, Sn strongly retards the eutectoid reaction of CGI, and ferrite fraction will increase markedly if Sn content decreases.
Besides, Mo has little effect on the ferrite and is in favor of improving the strength of CGI. As a result, in order to reach the goal of ductility greater than 4\% in CGI, Sn shouldn't be added and the addition of Si should be more than $2.3 \%$ and less than $2.7 \%$, while Mo and Ni can be used as strengthening elements and do not decrease the ductility obviously.

\subsection{Thermal conductivity}

In order to give an overall impression of the effects of vermicularity and ferrite fraction on the thermal property, all thermal data of CGI with $\mathrm{Sn}$ and without Mo or Ni were put together, as shown in Fig. 6 and Fig. 7. Figure 6 illustrates the relationship between thermal conductivity and vermicularity. It can be seen that an increase in vermicularity moderately improves the thermal properties as widely acknowledged ${ }^{[12,14]}$. From the trend of the conductivity, vermicularity must be more than $85 \%$ to meet the thermal conductivity of $40 \mathrm{~W} \cdot \mathrm{m}^{-1} \cdot \mathrm{K}^{-1}$. The positive effects of ferrite on thermal conductivity also appear in Fig. 7, but the points are dispersive, not aggregating closely like that of vermicularity, indicating that vermicularity plays a more important role in terms of conductivity ${ }^{[20,21]}$. 


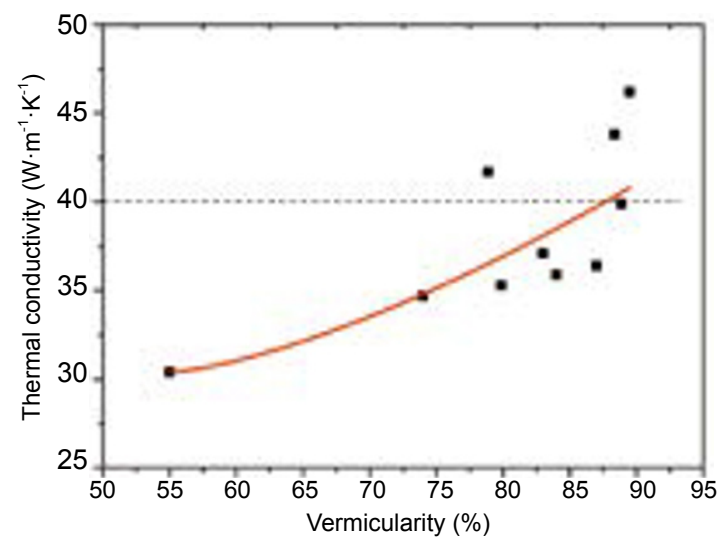

Fig. 6: Influence of vermicularity on thermal conductivity

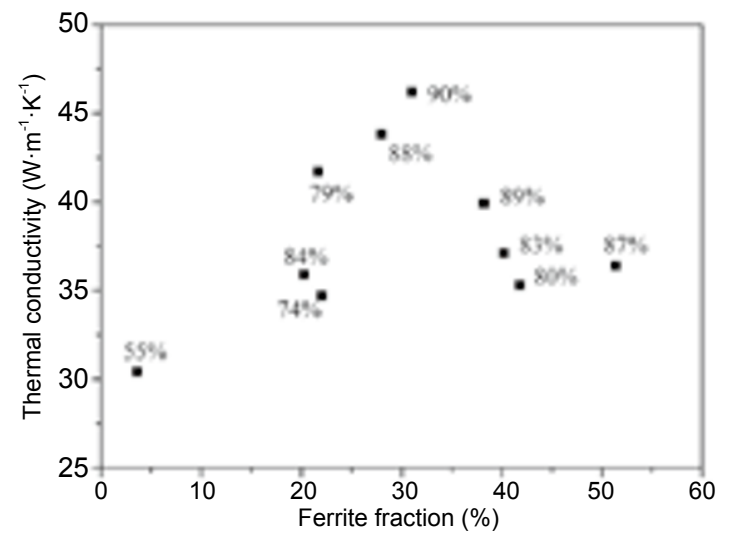

Fig. 7: Influence of ferrite on thermal conductivity, where the percent is the value of vermicularity

To investigate the effects of $\mathrm{Si}, \mathrm{Sn}, \mathrm{Mo}$, and $\mathrm{Ni}$ on thermal conductivity, the reference sample must have similar vermicularity. So the influence of $\mathrm{Si}$ was investigated by comparing casting No. 3 with casting No. 4 (Fig. 8). Notably, there is an obvious decrease of thermal conductivity, about 10 $\mathrm{W} \cdot \mathrm{m}^{-1} \cdot \mathrm{K}^{-1}$, when the content of Si increases from $2.33 \mathrm{wt} . \%$ to 2.76wt.\%, which can be explained by dissolving $\mathrm{Si}$ in ferrite as stated before ${ }^{[12]}$. Even though the depressing effects of $\mathrm{Sn}$ and $\mathrm{Ni}$ on thermal conductivity are similar according to the figure, it is worth noting that the addition of $\mathrm{Sn}$ is less than $\mathrm{Ni}$, which implies that $\mathrm{Sn}$ has a more deleterious effect on the thermal conductivity by strongly inhibiting the formation of ferrite. By the comparison between casting No. 7 and casting No. 8 , it is clearly seen that Mo has no evident effect on thermal conductivity. As discussed in section 2.1, Ni and Mo have similar effects on the ferrite fraction. So the difference between the effects of $\mathrm{Ni}$ and Mo on the thermal conductivity is related to the solid solubility of the elements in the ferrite rather than the ferrite fraction. The total thermal conductivity consists of phonon and electronic thermal conductivity, but the electronic contribution is greater ${ }^{[22]}$. The misfit between Ni and $\mathrm{Fe}$ is smaller than that between $\mathrm{Mo}$ and $\mathrm{Fe}$, which makes phonon conductivity after adding Ni greater. However, the solid solubility of $\mathrm{Ni}$ in ferrite is greater than the solubility of Mo ${ }^{[23]}$, causing the stronger scattering of the electrons, leading to a shorter mean free path, and decreasing the electronic thermal conductivity. Consequently, the negative effect of $\mathrm{Ni}$ on the total

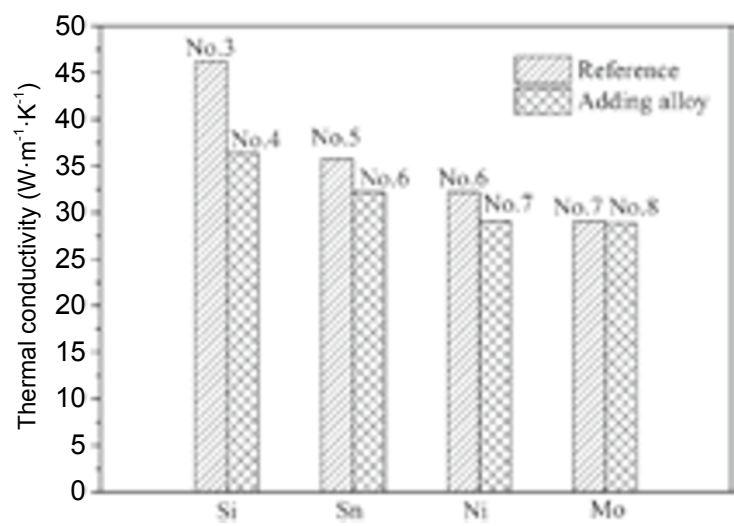

Fig. 8: Effects of $\mathrm{Si}, \mathrm{Sn}, \mathrm{Mo}$, and $\mathrm{Ni}$ on thermal conductivity

thermal conductivity is greater than the effect of Mo. Therefore, the order of greatest reduction in thermal conductivity is $\mathrm{Sn}, \mathrm{Ni}$, and Mo.

\section{Conclusions}

The effects of Si, Sn, Mo, and Ni on ferrite fraction and thermal conductivity of CGI were discussed and the main conclusions were summarized as follows:

(1) It is found that ductility is in direct proportion to ferrite fraction of CGI with similar vermicularity. Due to the excellent ability of graphitization, Si contributes to the growth of ferrite but the addition must be suitable to acquire good ductility. Other alloying elements, i.e., Sn, Mo, and $\mathrm{Ni}$, have negative effects on the ferrite as well as the ductility.

(2) DSC experiments were carried out to further investigate the influence of $\mathrm{Sn}$ and Mo on eutectoid reaction, and the comparison of DSC profiles during heating and cooling processes was taken into account. The results showed that Sn strongly retards the ferrite transformation, while Mo has unobvious effects.

(3) The effects of vermicularity and ferrite fraction on thermal conductivity have been given. Conductivity is in a direct proportion to these two factors, and vermicularity has a more impact than ferrite.

(4) The order among the negative effects of the alloying elements on thermal conductivity of CGI, from large to small, can be concluded as $\mathrm{Sn}, \mathrm{Ni}$, and Mo.

(5) To obtain better comprehensive properties combining ductility and thermal conductivity more than $4 \%$ and $40 \mathrm{~W} \cdot \mathrm{m}^{-1} \cdot \mathrm{K}^{-1}$, respectively, $\mathrm{Sn}$ and $\mathrm{Ni}$ are proposed to be out of the CGI, Si should be restricted in $2.3 \%-2.7 \%$, and Mo can be added moderately.

\section{References}

[1] Liu X, Yue Z, and Zhang B, et al. Study on the Thermal Fatigue Resistance of Grey Cast Iron. Foundry, 1989: 6-9. (In Chinese)

[2] Selin M, Holmgren D, and Svensson I L. Influence of alloying additions on microstructure and thermal properties in compact graphite irons. Int. J. Cast Metal Res., 2009, 22: 283-85.

[3] Konig $M$ and Wessen $M$. Influence of alloying elements on 
microstructure and mechanical properties of CGI. Int. J. Cast Metal Res., 2010, 23: 97-110.

[4] Johnson W C and Kovacs B V. The effect of additives on the eutectoid transformation of ductile iron. Metall. Trans. A, 1978, 9: 219-29.

[5] Lacaze J, Boudot A, Gerval V, et al. The role of manganese and copper in the eutectoid transformation of spheroidal graphite cast iron. Metall. Trans. A, 1996, 28: 2015-25.

[6] Sertucha J, Larrañaga $P$, Lacaze J, et al. Experimental investigation on the effect of copper upon the eutectoid transformation of as-cast and austenitized spheroidal graphite cast iron. Int. J. Metalcast., 2010, 4: 51-58.

[7] Lacaze $\mathrm{J}$ and Sertucha J. Effect of $\mathrm{Cu}, \mathrm{Mn}$ and $\mathrm{Sn}$ on pearlite growth kinetics in as-cast ductile irons. Int. J. Cast Metal Res., 2016, 29: 72-77.

[8] Holmgren D, Dioszegi A, and Svensson I L. Effects of nodularity on thermal conductivity of cast iron. Int. J. Cast Metal Res., 2007, 20: 30-40.

[9] Velichko A, Wiegmann A, and Muecklich F. Estimation of the effective conductivities of complex cast iron microstructures using FIB-tomographic analysis. Acta Mater., 2009, 57: 50235035.

[10] Konig M. Literature review of microstructure formation in compacted graphite Iron. Int. J. Cast Metal Res., 2010, 23: 185-92.

[11] Shi D Q, Kang K J, and Gao G L. System and Experiment on Fast Testing Vermicular Graphite Percent in Cast Iron Based on Ultrasonic Longitudinal Wave. Mater. Trans., 2016, 57: 544-548.

[12] Holmgren D. Review of thermal conductivity of cast iron. Int. J. Cast Metal Res., 2005, 18: 331-345.
[13] Rukadikar M C and Reddy G P. Influence of chemical composition and microstructure on thermal conductivity of alloyed pearlitic flake graphite cast irons. J. Mater. Sci., 1986, 21: 4403-10.

[14] Selin M, and Konig M. Regression Analysis of Thermal Conductivity Based on Measurements of Compacted Graphite Irons. Metall. Trans. A, 2009, vol. 40A: 3235-3244.

[15] Gerval V, and Lacaze J. Critical Temperature Range in Spheroidal Graphite Cast Irons. ISIJ Int., 2000, 40: 386-392.

[16] Lacaze $\mathrm{J}$ and Gerval V. Modelling of the Eutectoid Reaction in Spheroidal Graphite Fe-C-Si Alloys. ISIJ Int., 1998, 38: 71422.

[17] Littmann M. Iron and silicon-iron alloys. IEEE Trans. Magn., 1971, 7: 48-60.

[18] Yuan W J, Li R, and Shen Q. Characterization of the evaluation of the solid solubility of $\mathrm{Si}$ in sintered Fe-Si alloys using DSC technique. Mater. Charact., 2007, 58:376-79.

[19] Przeliorz R and Piatkowski J. Investigation of phase transformations in ductile cast iron of differential scanning calorimetry. IOP Conf. Ser.: Mater. Sci. Eng., 2011, 22.

[20] Blackmore P A, Morton K. Structure-property relationships in graphitic cast irons. Int. J. Fatigue, 1982, 4:149-55.

[21] Holmgren D, Dioszegi A, Svensson I L. Effects of Carbon Content and Solidification Rate on the Thermal Conductivity of Grey Cast Iron. Tsinghua Sci Technol., 2008, 13: 170-76.

[22] Williams R K, Graves R S, Weaver F J, et al. Yarbrough. Effect of point defects on the phonon thermal conductivity of bcc iron. J. Appl. Phys., 1987, 62: 2778-83.

[23] Parker R, Smith M S. The solubility of nickel in nickel ferrite. J. Phys. Chem. Solids., 1961, 21: 76-80. 